\title{
Educational Potential of Eco-Design of the Metropolis Urban Environment
}

\author{
Elena Krotova1", Natalia Demidova', Galina Kamerilova', Nadezhda Kiseleva', \\ Elena Perevoshchikova' ${ }^{1}$ and Elena Petrova ${ }^{2}$ \\ 'Minin Nizhny Novgorod State Pedagogical University, Nizhny Novgorod, Russia;krotova-ea@mail.ru, \\ demidovanngeo@yandex.ru,kamerilova-galina@rambler.ru,sopr@dront.ru,perevoshikovaen@mail.ru \\ ${ }^{2}$ The Nizhny Novgorod State Architectural and Construction University, Nizhny Novgorod, \\ Russia; petrova-e1@yandex.ru
}

\begin{abstract}
Background: The study was carried out in the scientific research laboratory of the Urban Eco-design as part of the research project "Theory and Methodology of Research on Eco-design of the Metropolis Urban Environment: Scientific and Educational Discourse", done at the Minin Nizhny Novgorod State Pedagogical University in the framework of the state project N 2014/362. Methods: The methodological tools used in the research include interconnected system of synergetic, environmental, ecological, cultural and historical approaches, seen from the perspective of sustainable development, as well as corresponding basic methods: information search, system structural analysis, the methods of functional integration, retrospective reflection, expert diagnostics, scientific forecasting. Findings: The article presents the results of the conducted research which enabled to determine the educational potential of a new cultural integrative area - eco-design of a metropolis. The article states the relevance of eco-design as it allows implementing the environmental approach when designing the urban environment for the purpose of harmonizing the relations in the urban system "the man and the nature" and increasing the man's responsibility for it. These scientific findings are of certain theoretical and practical value, they can also become the basis for further research regarding the conceptual development of theoretical and methodological grounds and methods of studying ecodesign from the perspective of pedagogical innovations. This research is the first attempt to provide a scientific definition of the categories and educational mission of eco-design of the urban environment, and it is understood as an instructional setting with a high potential for forming values, developing cognitive abilities and skills as well as creativity and personality in general. The authors identify and prove the conceptual framework, which include the leading ideas and principles of the ecological design of the metropolis urban environment. The article presents a pedagogical model for studying eco-design of the urban environment on three levels: theoretical and methodological, psychological and pedagogical, individual and didactic. The authors have devised the software and methodological support for the study of eco-design in the metropolis urban environment including original programs and manuals. Applications/Improvements: The study findings can be used by professionals working in the field of environmental education and can be implemented in the course of urban eco-design by the bachelors of environmental, architectural and construction university programs.
\end{abstract}

Keywords: Eco-Design, Environmental Consciousness, Educational Potential, Metropolis, Urban Environment

\section{Introduction}

Modern challenges rising as a result of urbanization increased the public awareness of the importance of urban eco-design as a method of solving environmental problems in large cities. Creating a comfortable and environmentally friendly urban environment by means of eco-design can meet a wide range of human needs without disrupting the biological balance. Consequently, a specific feature of the urban design is its environmental responsibility, social responsiveness, efficiency, i.e. its focus on achieving harmonious sustainable development of the nature and society.

The phenomenon of ecological design, first investigated in the works of $\mathrm{J}^{1-4}$ is considered within as a cultural and ecological concept, whose main purpose 
is preservation of spiritual and cultural memory. The research papers ${ }^{5,6}$, emphasize the need for treating the regional and national traditions carefully, which includes the natural landscape, objects and spaces, structural and graphic urban planning. A new phenomenon in this field, eco-design ${ }^{7}$ combines artistic and scientific approaches, rational and irrational aspects of design and creative activities in a systematic way, providing a single holistic view on the urban metropolis environment ${ }^{8-16}$.

Combining scientific and artistic opportunities for exploring reality, eco-design is a specific artistic and design type of creativity, with a rigorous scientific method forming its base. Eco-design brings modern integrative ideas into the urban environment which combines scientific, humanitarian and artistic areas. This synthesis provides a holistic view on the diversity of the environment and enables the urban community to effectively participate in the discussion and solution of environmental problems. Eco-design allows forming new environmental needs and activities based on environmental consciousness ${ }^{17,18}$.

At the same time, certain theoretical and environmental aspects of eco-design, actively developed in the general context, have not been properly investigated yet, especially regarding the perception, design and development of the urban environment. Here we should mention one more important aspect of eco-design. Due to its potential, urban eco-design is capable of playing the leading part in dealing with the issues associated with an individual's development, the emergence of his subjectivity, environmental consciousness, which also requires a serious theoretical analysis and devising specific methodological guidelines. We strongly believe that, as far as the urban environment is concerned, ecodesign performs two major functions, involving not only the improvement of human living environment, but also educating an ecologically literate person responsible for his living environment and maintaining the balance between the man and the nature.

\section{Concept Headings}

Humanistic perspective of the research, typical of postmodernist era, states that the man is inevitably involved in the consideration of the urban environment. The urban environment as a socio-natural phenomenon represents a time-space unity of the nature, population, economy, which develops according to probabilistic laws of causality, on the basis of co-evolutionary principles. This approach develops the idea of the man and environment creating together, which is seen as an indicator of the integral whole ("personality traits - environmental qualities"), when the quality of the environment is determined by the environmental consciousness of its inhabitants. In this regard, the mission of urban eco-design is not only to provide an innovative approach to designing a city to ensure its sustainable development. Educating an ecologically literate person is an equally important task. In other words, forming the man who is aware of his direct link to the environment, his responsibility for it condition, his ability and commitment to its conservation and restoration, i.e. the man of a new type of culture.

Research on the main features of eco-design of the metropolis urban environment enabled us to define its fundamental philosophical meaning in understanding both scientific and educational aspects.

The conceptual framework for urban eco-design was developed on the basis of the following ideas:

- universal unity of the continuous nature of the world and the man;

- perception of the urban ecological world as the environment characterized by the system integrity, significant information content, broad educational opportunities, openness, dynamism, historicity, emergence, regional specificity;

- perception of the urban environment as a socionatural phenomenon, developing according to the laws of probability after the principles of co-evolution;

- collaborative creativity of the man and the urban environment as an indicator of their interrelated wholeness ("personality traits - characteristics of the environment"), when the environment features are defined by the environmental consciousness of its inhabitants;

- integration of logical rational and irrational ways of learning and thinking when developing the environment, considering its current issues, interdisciplinary approach, predictability, phenomenological and antireductionist approaches;

- specific paradigm, according to which the urban environment is the object of study and design by a researcher placed inside this system;

- "behavioral situation" seen as a structural unit of the eco-design which reflects current environmental ideas, historical circumstances and local traditions;

- organic synthesis of artistic and scientific system approaches, bringing new socio-eco-cultural ideas into 
the environment, uniting the historically established architectural space and the modern man's universe.

In the course of the research we generalized and systemized the existing theoretical approaches and original ideas, which allowed us to formulate the system of the leading principles enabling the development of eco-design of the metropolis urban environment:

- cultural ecological principle which sets the direction of eco-design development, depending on the dominant cultural values of modern social development aimed at sustainability, democracy, openness and tolerance. Environmental consciousness reflects the co-evolutionary values of the interrelated socio-natural development and has a powerful consolidating potential. Eco-design enables to implement these eco-humanistic ideas and enriches a typical urban planning with new environmental ideas concerning the city's design and construction;

- system synergetic principle involves the analysis of urban eco-design as an integrated, open, non-linearly developing system and is based on the principles of self-organization, complementarity, simulation of the alternative options of the environment greening;

- environmental principle which considers human needs, reflected in practical, technical and socio-cultural (including aesthetic) features of the urban environment;

- artistic and aesthetic principle focuses on devising eco-design regarding its artistic merit and making a human life more comfortable;

- historical and reflective principle which enables to use the positive experience of the past for reaching beauty and harmony, preserving national traditions;

- regional principle, involving the use of local cultural and historical traditions in design and other visual, social, psychological, functional, symbolic and symbolic contexts, while preserving the natural landscape.

This generalization of the principles of urban eco-design allows us to consider the city in the unity of its interrelated functional space-time coordinates: culture-generating constructive ideas, innovative design, artistic expression, scientific system approach. Each of them reflects the values, cognitive, activity-related, personal aspects of the high educational potential of eco-design of the urban environment.

\section{Results}

The new approach to design reflects innovative methodology of constructing the eco-design of a city, according to which it is understood as an educational environment, a new prognostic educational perception of the designed object. This approach embraces the artistic modeling and compositional form making, thus it can be said that eco-design implements the principles of integrity, harmony, culturology, meaning-generation and ecology. Various cultural ecological models of the urban educational environment are being formed in the city.

Due to its potential educational opportunities, urban eco-design takes the central position regarding the issues associated with the development of an individual, the development of one's subjectivity. This global educational goal is the dominant one, and it requires a comprehensive study at its theoretical, methodological, psychological, pedagogical, individual didactic levels.

The theoretical and methodological level, including scientific ideas and concepts of sustainable development, post-non-classical science, postmodernism, ecological humanism, co-creation, tolerance, regulate the general parameters of the research and its basic provisions; this allowed us to define the essential features of urban eco-design and its growing importance in creation of a harmonious living environment.

The psychological and pedagogical level, actually representing the pedagogical discourse, focuses on the development of subjectivity in the learning process and environmentally friendly transformation of the urban living environment which does not threaten the ecology. The central idea of personal development ${ }^{19,20}$ becomes the key one for the approach. Collaborating with other people in social and cultural activities, a person reaches a higher level of his development, moving from interpsychic to intrapsychic.

The individual didactic level is represented by the methodological discourse, on the basis of which we have built an eco-humanistic model of education "Eco-design of the Urban Environment: towards Harmony between the Man and the Nature".

The approach, chosen for this study and involving the abovementioned levels, allowed us to devise a three-component model: a goal as an ideal, a goal as a means, a goal as a subject. On its highest level, the goal which is defined as an ideal sets a general strategy of education aimed at the formation of the environmental consciousness of an individual. The second level, the goal as a subject, implies ecological competence, seen as a mandatory prerequisite for the formation of environmental consciousness. On the third level, the goal as a means stands for planned educational outcomes 
regarding social, personal, educational, regulatory, communicative development of a student.

The route enabling the achievement of the goal includes a two-component integrative content of urban eco-design: the external one which reflects the structure of environmental consciousness and the internal one the contents acquired by a person. The dialectical unity of artistic expression and scientific consistency of eco-design allows expansion and development of the educational contents by increasing its emotional and sensual aspects, integration of the systematic knowledge, involvement of various artistic and scientific methods of cognition.

The axiological aspect of the educational contents represents a set of value categories: the system of ecohumanistic values and attitudes formed by the eco-design of urban environment (the importance of synthesizing the global and the regional in eco-design, the role of traditions and innovations, environmentally-friendly activities).

The cognitive aspect of the contents involves consideration of the following aspects of urban ecodesign:

- values and meaning - "The purpose of urban ecodesign is harmonizing the relationship between the man and the nature";

- historical perspective and self-reflection - "Cultural origins and evolution of urban eco-design";

- the essence and meaning - "Urban eco-design as a special design and artistic activity";

- prospects - "Main areas and principles of the urban eco-design". Praxeological aspect of the contents materializes the design and artistic activities of an individual through a variety of environmental actions.

At the current stage of education development, the principle of fundamentality is understood as the main prerequisite for development. As a result, the focus of the educational content moves from empirical to the conceptual framework by means of accumulating the information around the basic cultural and environmental concepts, urban eco-design being one of them. The input data of urban eco-design of the metropolis acts as the "bearing frame" for environmental education regarding relations between the urban population and the nature. Representing the essential features of phenomena and processes, these concepts enable the implementation of scientific approaches, artistic principles, laws and concepts of the urban environment optimization by means of eco-design.
The procedural component of the model consists of three levels which represent the progressive stages of the material comprehension and use of appropriate educational technologies: 1) emotional sensory perception where motivation is formed by the visual image of the background, attention to unusual objects (graffiti, unique design of pedestrian streets, paintings on buildings; 2) conscious perception which implies the formation of the cognitive basis for environmental consciousness as a system of interdisciplinary knowledge in the field of urban eco-design, as well as research methods of artistic and scientific activities; 3 ) artistic and practical creativity which emphasizes environmental, resourcesaving, restorative, and eco-design practical activities. Understanding the essence of these activities facilitates social and environmental actions, a person's further ecocultural self-development and self-realization.

As part of this research, we defined the role of interactive forms and methods of training when investigating ecodesign of the urban environment. For example, at the first stage we used the methods that register the value and emotional appeal of the objects of eco-design promoting self-identification of an individual in a large city. These include methods of artistic representation, identification, labilization, associations, and empathy. Students participate in the motivational, emotional, selfrepresenting and spiritual dialogues. Special attention is paid to interactive methods and forms, "allowing students to meet" with a real social and natural environment of the metropolis. Defining ecological-related personal meanings is made possible by involving students into searching-for-meaning, critical, reflective dialogue, active participation in role-plays, simulation games, and design projects.

Creative aspects of studying the metropolis ecodesign are implemented through the methods which imply students' co-creative interaction with the urban environment, such as ritualization of environmental practices, environment protection, reflection on various environmental issues. Students participate in a selfrepresentation and creative dialogue, fulfill their potential in practice-oriented eco-design projects, as well as activities meaningful for an individual and the society.

Environmental consciousness is generally assessed by registering the level of ecological competence: unconscious competence, conscious incompetence, conscious competence and unconscious competence ${ }^{17,21}$, successfully applied by us earlier ${ }^{22}$. The basis for this 
procedure is made up by the reflection and evaluation of the material comprehension, eco-humanist values, knowledge, skills, and creative work methods.

\section{Discussion}

As a new trend, eco-design is a subject for extensive interdisciplinary research carried out by the experts in industrial, graphic, interior and other types of design, as well as environmental design. Another significant aspect worth mentioning is a growing cultural environmental emphasis from a number of studies which consider ecodesign as a method of harmonizing the relationship between people and the nature. Considering theoretical and methodological aspects of the research on urban ecodesign of a metropolis in the educational context, we can conclude that it is necessary to find the interrelated links between its scientific meaning and the values and beliefs of the modern education. It has been stated that the modern philosophy of education considers the environment as the most important factor of an individual's socialization and development - as "the source of all specific features of a personality or the source of social development"19. In this study, the urban environment of a metropolis is understood as an educational environment which incorporates a wide range of predetermined development opportunities for an individual regarding one's environmental consciousness. This eco-cultural educational environment can be perceived only from within by the consciousness being its part. And, due to its creative potential, the design considers the man as a new "active agent", responsible for the quality of his living environment. We believe that the ability to generate elements of culture in the environment is a specific feature of ecodesign which allows us to describe it as a powerful influence on the consciousness and behavior of the man. Information, graphic, semantic, symbolic components of urban eco-design act as educational mechanisms promoting the formation of an individual's environmental consciousness in the perfect balance of values, cognitive, practical, and personal aspects.

\section{Conclusion}

Innovative cultural and eco-humanistic trends, values and ideas of modern environmental education have shifted its focus towards achieving personally and socially significant results as well as eco-cultural development of a human in close connection with the quality of the urban environment.

It has been stated that, due to its specific features, eco-design of the urban environment plays an active part in the formation of the environmental consciousness of an individual, developing such qualities as empathy, tolerance, being open to dialogue, responsibility and readiness to participate in the environmental protection and improvement. Eco-design removes the contradiction between the universal and the particular, facilitating the formation of ecologically and culturally conscious individuals - citizens of their country and the world, without losing national identity and ethnic past, who actively participate in the study and infrastructure development of the city. The following approach implies using the acquired resources of one's cultural and environmental traditions as well as the global experience. Urban eco-design, aimed at the harmonious co-evolutionary development of the human and natural worlds, helps to understand their close connection and the need for treating them with care. This is how its potential of environmental protection can be realized. Along with the general standardization of education, such an approach allows reflecting the unique character of each individual and his personality.

Eco-design enables to enrich, develop and update the contents of environmental education with integrative ideas, which combine natural sciences, humanities and arts, previously considered separately, thereby providing a holistic view of the outside world.

Systematic, consistent formation of the environmental consciousness of an individual will be facilitated by a pedagogical model for studying urban eco-design which was developed in the course of the study. This model takes into account the hierarchical levels of the methodology of educational research: theoretical and methodological, psychological and pedagogical, individual and didactic.

It should also be noted that the study findings regarding its various theoretical, methodological and methodical aspects have been tested in different practical situations, including the development of a large set of educational programs and textbooks $s^{6,23,24}$.

\section{Acknowledgements}

The study was carried out as part of the research program "Theory and Methodology of Research on Eco-design of the Metropolis Urban Environment: Scientific and 
Educational Discourse", done at the Minin Nizhny Novgorod State Pedagogical University in the framework of the state project N 2014/362.

\section{References}

1. Ruskin J. The nature of gothic. The stones of Venice, Vol. II. Date accessed: 26/02/2016: Available from: http://www47. homepage.villanova.edu/seth.koven/gothic.html.

2. Ruskin J. Dover Publications: The seven lamps of architecture. 1989.

3. MacCarthy F. London: National Portrait Gallery: Anarchy and Beauty: William Morris and his Legacy. 2014; p. 18601960.

4. Maldonado T. New York: Harper \& Row: Towards an ecological rationalism. 1972.

5. Kagan MS. Culture of a city and ways of its study. St. Petersburg: Krupskaya SPbSIC: City and culture: Collected scientific works. 1992; p. 15-34.

6. Kondratieva KA. Moscow: Stroganov Moscow State University of Arts and Industry: Design and ecology of culture. 2000.

7. Demidova NN, Kamerilova GS, Matveeva AV. System of forming environmental competence based on studying live nature of the urbanized environment of a megapolis: theoretical and methodological foundations and methodological model. Bulletin of Minin University, 2014; 2. Date accessed: 26/02/2016: Available from: http://vestnik. mininuniver.ru/reader/search/sistema-formirovaniya-ekologicheskoy-kompetentnost/

8. Sitte C, Collins CC, Collins GR. New York: Dover Publications: Camillo Sitte: The Birth of Modern City Planning. 2006.

9. Lynch K. England: MIT Press, Massachusetts Institute of Technology: The image of the city. Cambridge, Massachusetts and London. 1960.

10. Hearn MF. Massachusetts London, England: The MIT Press: Ideas that shaped buildings. 2003.
11. Bagnasco A, Le Gales P. Paris: La Decouverte, coll. Recherches: Villes en Europe. 1997.

12. Bagnasco A, Barbagli M, Cavalli A. Corso di sociologia. 2012. Date accessed: 26/02/2016: Available from: http://ru. bookzz.org/book/2315521/b20cab.

13. Le Gales P. New York, Oxford, Oxford: University Press: European cities: social conflicts and governance. 2002.

14. Scholte JA. Warwick: University of Warwick: Global civil society: Changing the world. CSGR Working Paper. 1999; p. 1-35.

15. Scholte JA. Houndmills. New York: Palgrave Macmillan: Globalization. A critical introduction. 2005; p. 67-74.

16. Uvarov AV. Environmental design: the experience of studying the processes of artistic design. 2010. Date accessed: 14/10/2015: Available from: http://www.dslib.net/tech-estetika/jekologicheskij-dizajn-opyt-issledovanija-processov-hudozhestvennogo-proektirovanija.html\#3800764.

17. Gehl J. Island Press: Washington: Cities for people. 2010.

18. Yanitskiy ON. Moscow: Mysl: Ecological prospect of the city. 1987.

19. Vygotsky LS. Moscow: Education - Press: Educational Psychology. 1999.

20. Petrovskiy VA. Rostov-on-Don: Feniks: Personality in psychology, the paradigm of subjectivity. 1996.

21. Plunkett LC, Hale GA. New York: John Wiley \& Sons Inc.: The proactive manager: the complete book of problem solving and decision making. 1981.

22. Demidova NN, Kamerilova GS. Nizhny Novgorod: Minin University: Methodology of the environmental audit of the urban area. Study guide. 2014.

23. Demidova NN, Kamerilova GS. Nizhny Novgorod: Minin University: Basics of eco-design of the urban environment. Textbook. 2014.

24. Demidova NN, Kamerilova GS. Theoretical aspects of ecodesign of the urbanized environment. Modern issues of science and education, 2014 May 20; 3. Date accessed: 26/02/2016: Available from: http://www.science-education. $\mathrm{ru} / 117-13155$. 